\title{
Interaction between Wine Phenolic Acids and Salivary Proteins by Saturation-Transfer Difference Nuclear Magnetic Resonance Spectroscopy (STD-NMR) and Molecular Dynamics Simulations
}

\author{
Raúl Ferrer-Gallego, ${ }^{\dagger, \#}$ José Miguel Hernández-Hierro, ${ }^{\S ®}$ Natércia F. Brás, ${ }^{\otimes}$ Nuno Vale, ${ }^{\otimes}$ Paula Gomes, ${ }^{\otimes}$
} Nuno Mateus, ${ }^{\perp}$ Victor de Freitas, ${ }^{\perp}$ Francisco J. Heredia, ${ }^{\circledR}(0)$ and María Teresa Escribano-Bailón ${ }^{*}{ }^{\dagger}(1)$

${ }^{\dagger}$ Grupo de Investigación en Polifenoles, Unidad de Nutrición y Bromatología, Facultad de Farmacia, University of Salamanca, 37007 Salamanca, Spain

\#VITEC, Parc Tecnològic del Vi, 43730 Falset (Tarragona), Spain

${ }^{\S}$ Food Colour and Quality Laboratory, Department of Nutrition and Food Science, Facultad de Farmacia, Universidad de Sevilla, 41012 Sevilla, Spain

${ }^{\otimes}$ UCIBIO, REQUIMTE, Departamento de Química e Bioquímica, Faculdade de Ciências, Universidade do Porto, Rua do Campo Alegre s/n, 4169-007 Porto, Portugal

${ }^{\perp}$ LAQV-REQUIMTE, Departamento de Química e Bioquímica, Faculdade de Ciências, Universidade do Porto, $4169-007$ Porto, Portugal

\section{Supporting Information}

ABSTRACT: The interaction between phenolic compounds and salivary proteins is highly related to the astringency perception. Recently, it has been proven the existence of synergisms on the perceived astringency when phenolic acids were tested as mixtures in comparison to individual compounds, maintaining constant the total amount of the stimulus. The interactions between wine phenolic acids and the peptide fragment IB7 12 have been studied by saturation-transfer difference (STD) NMR spectroscopy. This technique provided the dissociation constants and the percentage of interaction between both individual and mixtures of hydroxybenzoic and hydroxycinnamic acids and the model peptide. It is noteworthy that hydroxybenzoic acids showed higher affinity for the peptide than hydroxycinnamic acids. To obtain further insights into the mechanisms of interaction, molecular dynamics simulations have been performed. Results obtained not only showed the ability of these compounds to interact with salivary proteins but also may justify the synergistic effect observed in previous sensory studies.

KEYWORDS: phenolic acid, saturation transfer difference NMR, protein interaction, astringency, molecular dynamics simulations

\section{INTRODUCTION}

Phenolics are characterized by presenting at least one aromatic ring with one or more hydroxyl groups attached. These phytochemicals are present in the epidermis of leaves and the skin of fruits throughout the plant kingdom and have important roles as secondary metabolites. ${ }^{1,2}$ Phenolic compounds are also responsible for important organoleptic properties of plants, fruits, and beverages, phenolic acids being the simplest structures with only a single benzene ring. Among organoleptic properties, astringency is an important one whose basic molecular mechanisms have not been fully understood so far. Nowadays, to evaluate the aforesaid attribute, sensory analysis is one of the most useful tools. ${ }^{3-5}$ Literature reporting the individual sensory profiles of phenolic compounds is scarce, although it is well documented that they contribute to the bitter and astringent oral sensation of foods and beverages. ${ }^{6-8} \mathrm{~A}$ number of studies have been focused on the interactions between phenolic compounds and proteins as mechanisms that could explain the perception of the astringency. ${ }^{8-12}$ Indeed, the interaction between phenolic compounds and salivary prolinerich proteins (PRPs) has been highly related to the astringency perception, and specific interaction between tannins and PRPs with or without the precipitation of the complex has been demonstrated. ${ }^{13}$ However, it has also been suggested that the interaction with salivary proteins does not explain all of the quality aspects of the astringency ${ }^{13,14}$ and that multiple mechanisms might occur simultaneously, such as the implication of the oral tissues. ${ }^{15,16}$ With regard to phenolics, their concentration and chemical structure play important roles in astringency, although concentration appears to be less important than the structure. ${ }^{17-22}$

Wine is one of the most consumed beverages in the world, and its quality depends on a number of factors. With regard to its sensory quality, astringency is one of the most relevant parameters to take into account. A broad range of phenolic compounds might contribute to this mouthfeel, among them the phenolic acids present in wine. The predominant phenolic acids in wine are hydroxylated derivatives of benzoic acid and

Special Issue: XXVIIIth International Conference on Polyphenols 2016

Received: December 2, 2016

Revised: February 28, 2017

Accepted: March 2, 2017

Published: March 2, 2017 


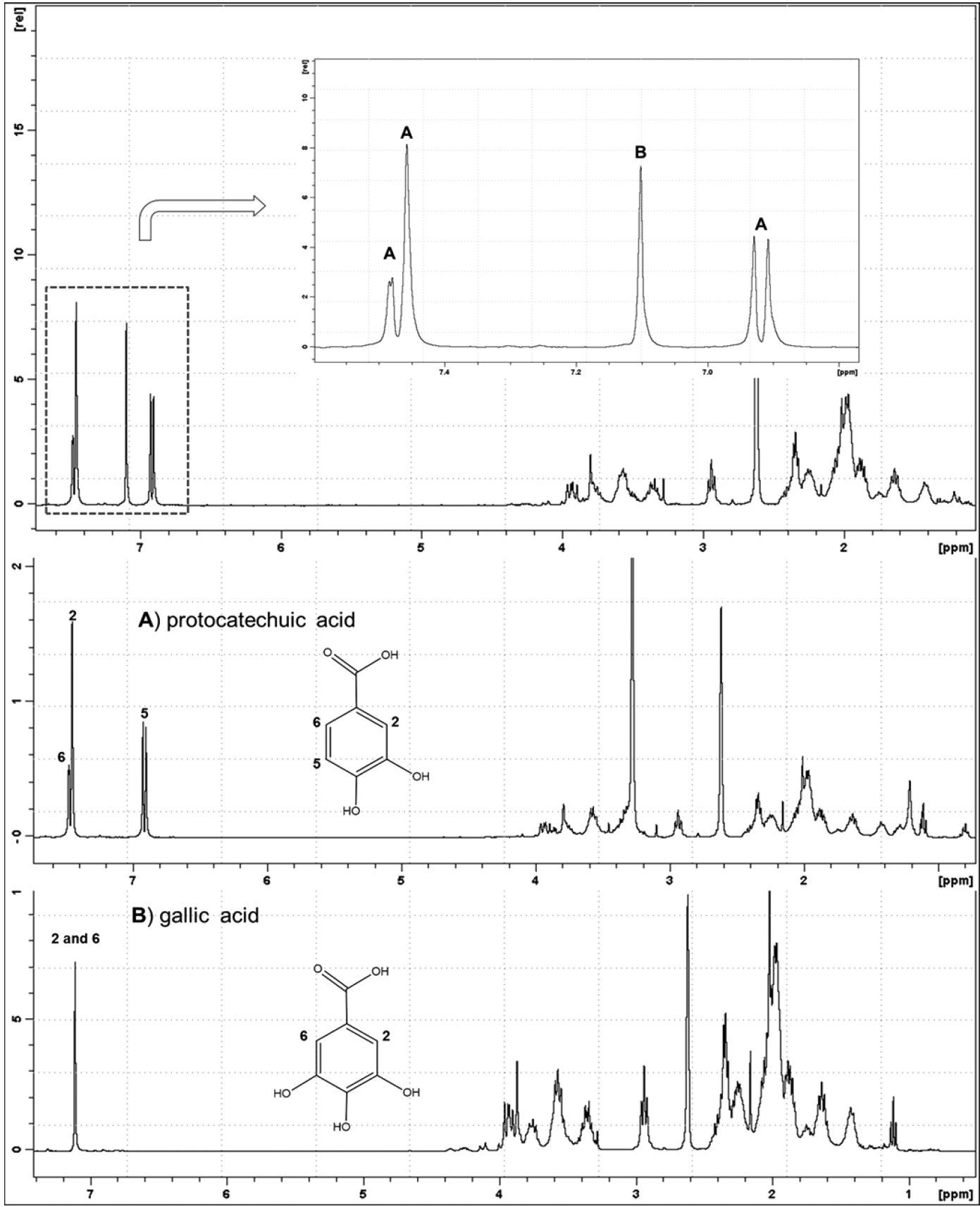

Figure 1. Spectra from STD-NMR titrations for both mixtures of hydroxybenzoic acids and individual compounds (A, protocatechuic acid; B, gallic acid) and the model peptide IB7 $7_{12}$. Final concentrations of acids were from 0.2 to $1.8 \mathrm{mM}$, and peptide concentration was constant (0.5 mM) throughout the STD titration experiment. Proton assignments in both chemical structure and NMR spectra are also shown.

cinnamic acid. Recently, it has been observed the existence of synergism of astringency when phenolic acids were tested as a mixture in comparison to individual compounds, maintaining the total amount of the stimulus constant. ${ }^{23}$ It was desirable to add to the knowledge of the interactions between these compounds and salivary proteins that could explain the synergistic effect observed and also postulate a tentative molecular mechanism to explain them.

Saturation-transfer difference (STD) NMR spectroscopy and molecular dynamics (MD) simulations have been jointly used to explain the interactions between other phenolic compounds and salivary proteins or representative peptide fragments with very promising results for tannins ${ }^{24-27}$ and also for anthocyanins. $^{28}$ However, no reference has been found that describes the interaction between phenolic acids and the peptide fragment $\mathrm{IB}_{12}$ using either STD-NMR or $\mathrm{MD}$ simulations.

The main purpose of this work was to study the interactions between wine phenolic acids and the peptide fragment $I B 7_{12}$ to add to the knowledge of the interactions between these compounds and salivary proteins. To our knowledge, this is the first time these tools have been jointly applied to face this goal taking into account these compounds. Furthermore, this is also the first time that the synergistic effect has been confirmed, and a tentative molecular mechanism has been also proposed to explain this effect observed in sensory studies. ${ }^{23}$ 

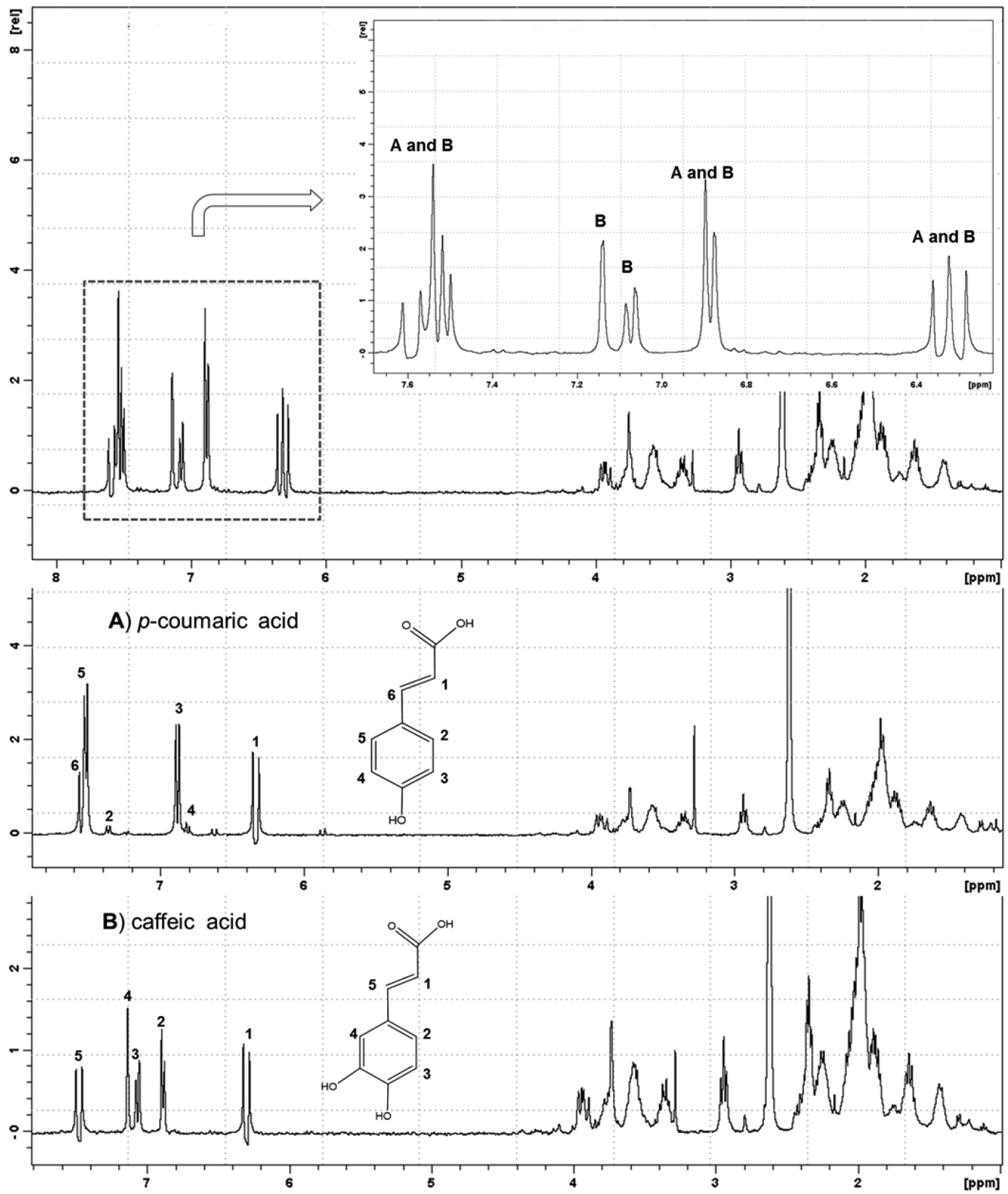

Figure 2. Spectra from STD-NMR titrations for both mixtures of hydroxycinnamic acids and individual compounds (A, $p$-coumaric acid; B, caffeic acid) and the model peptide $\mathrm{IB}_{12}$. Final concentrations of acids were from 0.2 to $1.8 \mathrm{mM}$, and peptide concentration was constant $(0.5 \mathrm{mM})$ throughout the STD titration experiment. Proton assignments in both chemical structure and NMR spectra are also shown.

\section{MATERIALS AND METHODS}

Reagents. All chemicals were of analytical reagent grade. Gallic acid, protocatechuic acid, caffeic acid, $p$-coumaric acid, deuterium oxide $(99.9 \%)$, and dimethyl- $d_{6}$ sulfoxide $(99.8 \%)$ were supplied by Sigma-Aldrich (St. Louis, MO, USA). The peptide IB7 of 12 amino acid residues, PGKPQGPPPQGG (C-terminal amide), which contains a characteristic sequence of proline-rich proteins, was synthesized as detailed elsewhere in Ferrer-Gallego et al. ${ }^{25}$ and was used in the STDNMR experiments.

STD-NMR Experiments. The lyophilized IB7 12 peptide $(0.55 \mathrm{mg})$ was dissolved in $1 \mathrm{~mL}$ of $\mathrm{D}_{2} \mathrm{O}$ (99.9\%) with $5 \%$ of dimethyl- $d_{6}$ sulfoxide (99.8\%). Different quantities of phenolic acids were added to the NMR tube to obtain a final concentration of acids ranking from 0.2 to $1.8 \mathrm{mM}$ and maintaining the peptide concentration constant $(0.5$ $\mathrm{mM}$ ) throughout the STD titration experiment. The selection of each phenolic acid concentration was restricted essentially by the detection limit in the STD experiment. Before titrations, several tests, with only the ligands (without peptide), were carried out to detect the maximum value of each acid without STD signal. After that, six titration experiments were carried out, four of them from each individual phenolic acid (gallic, protocatechuic, $p$-coumaric, and caffeic acids) and two of them from the mixtures of the hydroxybenzoic acids (gallic and protocatechuic acids) and hydroxycinnamic acids ( $p$-coumaric and caffeic acids).

Slight modifications from the previous parameters described in Ferrer-Gallego et al. ${ }^{25}$ were taken into account to record the STDNMR spectra. Briefly, NMR experiments were recorded on a Bruker Avance III $400 \mathrm{MHz}$ spectrometer, equipped with a $5 \mathrm{~mm}$ PABBI $1 \mathrm{H}$ / $\mathrm{D}-\mathrm{BB}$ and pulse gradient units capable of producing magnetic field pulsed gradients in the $z$ direction of $50 \mathrm{G} / \mathrm{cm}$. The measurements were made with standard Bruker pulse sequences at $26{ }^{\circ} \mathrm{C} .{ }^{1} \mathrm{H}$ and STD spectra were recorded with a shaped pulse to suppress the water resonance using the following parameters: spectral width, $16 \mathrm{ppm}$; nutation angle, $7.8 \mu \mathrm{s}$ and $90^{\circ}$; and shaped pulse duration, $2 \mathrm{~ms}$. 
Table 1. STD-NMR Results for both Individual Phenolic Acids and Mixtures

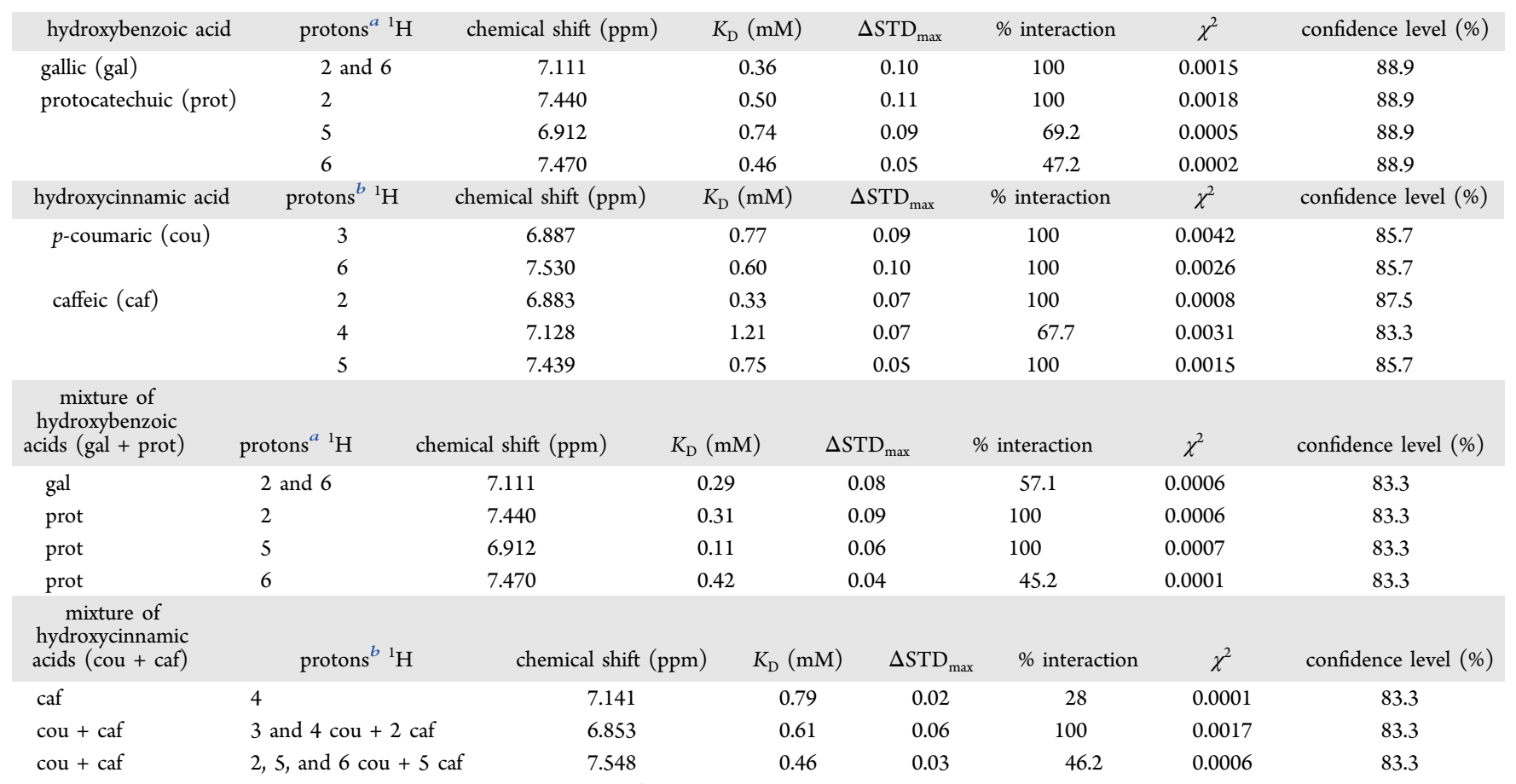

${ }^{a}$ For proton assignments, the reader is referred to Figure $1 .{ }^{b}$ For proton assignments, the reader is referred to Figure 2.

Selective saturation of the peptide off-resonance at $20 \mathrm{ppm}$ and onresonance at $-0.5 \mathrm{ppm}$ was performed using a pseudo-twodimensional (2D) sequence for STD with a shaped pulse train alternating between the on- and off-resonances. ${ }^{29}$ STD-NMR spectra were acquired using Gauss 1.1000 pulses for selective saturation (50 $\mathrm{ms}$ ), with a total saturation time of $2.5 \mathrm{~s}$. The number of scans (16), receptor gain value (287), and relaxation delay (3.5 s) were kept constant. To subtract the unprocessed on- and off-resonance spectra, to baseline correct the resulting difference spectrum, and to integrate the areas, TopSpin 2.1 software from Bruker was used.

The STD effect was determined using an amplification factor $\left(A_{\mathrm{STD}}\right)$ according to the equation ${ }^{30}$

$$
A_{\mathrm{STD}}=\frac{I_{0}-I_{\mathrm{SAT}}}{I_{0}} \times \frac{[\mathrm{L}]}{[\mathrm{P}]}=\frac{I_{\mathrm{STD}}}{I_{0}} \times \frac{[\mathrm{L}]}{[\mathrm{P}]}
$$

where $I_{\mathrm{SAT}}$ is the signal intensity of the selectively saturated peptide spectrum (on-resonance) and $I_{0}$ is the signal intensity of the spectrum recorded without peptide saturation (off-resonance). [L] is the concentration of the ligand and in this case corresponds to the acid concentrations, and $[\mathrm{P}]$ is the peptide concentration. The determination of the dissociation constant $\left(K_{\mathrm{D}}\right)$ was calculated according to eq 2 by a nonlinear least-squares-fitting curve using the Solver utility of Microsoft Excel.

$$
A_{\mathrm{STD}}=\frac{\alpha_{\mathrm{STD}} \times[\mathrm{L}]}{K_{\mathrm{D}}+[\mathrm{L}]}
$$

$\alpha_{\text {STD }}$ is the maximum amplification factor.

Optimization and MD Simulations. Molecular systems with proline-rich protein fragments called $\mathrm{IB} 7_{12}$ and several phenolic acids [gallic (gal), protocatechuic (prot), caffeic (caf), and p-coumaric (cou)] molecules were built. The amino acid sequence of $\mathrm{IB}_{12}$ is SPPGKPQGPPPQ. The Antechamber tool was used to parametrize the caf, cou, gal, and prot compounds, which was optimized with the HF/6-31G(d) level of theory by using the Gaussian 09 suite of programs. ${ }^{31}$ The RESP algorithm ${ }^{32}$ was used to get the atomic charges. Geometry optimization and MD simulations were carried out using the $\mathrm{GAFF}^{33}$ and $\mathrm{ff} 9 \mathrm{SB}^{34}$ force fields for phenols and peptides, respectively. An explicit solvation model (TIP3P waters) was included as a truncated rectangular box with a minimum distance of $15 \AA$ between the box edges and any atom within each system. Six MD simulations were performed with four IB7 $7_{12}$ peptides and (1) four gal and four prot, (2) eight gal, (3) eight prot, (4) four caf and four cou, (5) eight caf, and (6) eight cou. The phenolic acids were randomly placed around the peptides, reproducing the experimental conditions used. All system geometries were minimized in two stages. Subsequently, 100 ps of MD simulation with a NVT ensemble and considering periodic boundary conditions was performed, followed by $50 \mathrm{~ns}$ of MD simulation with an isothermal-isobaric NPT ensemble using the Langevin thermostat (collision frequency of $1.0 \mathrm{ps}^{-1}$ ) 35 and the Berendson barostat. All simulations were carried out using the AMBER $12.0^{36}$ simulation package. Bond lengths involving hydrogen atoms were constrained using the SHAKE algorithm, and the equations of motion were integrated with a 2 fs time step using the Verlet leapfrog algorithm. ${ }^{37}$ The particle-mesh Ewald (PME) method $^{38}$ was used to treat long-range interactions, and the nonbonded interactions were truncated with a $10 \AA$ cutoff. The MD trajectories were saved every 2 ps and were analyzed with the PTRAJ module of AMBER 12.0. ${ }^{36}$

\section{RESULTS AND DISCUSSION}

STD-NMR. Figure 1 shows the spectra from STD-NMR titrations for both individual and mixtures of hydroxybenzoic acids and the model peptide. Similarly, the corresponding information for both individual and mixtures of hydroxycinnamic acids is shown in Figure 2. Proton assignments in both chemical structure and NMR spectra are also shown in these figures. The aforesaid signals were used to calculate the relative STD-NMR effects following the previously mentioned methodology. ${ }^{30}$ Table 1 presents the dissociation constant $\left(K_{\mathrm{D}}\right)$ and maximum amplification factor $\left(\Delta S \mathrm{SD}_{\max }\right)$ parameters obtained in the nonlinear regression models. The aforesaid models have been evaluated via the chi-squared parameter $\left(\chi^{2}\right)$ and confidence level. Moreover, the percentage of interaction of each proton is also presented. According to these constants, the affinity of gallic acid $\left(K_{\mathrm{D}}=0.36 \mathrm{mM}\right)$ toward $\mathrm{IB} 7_{12}$ was generally higher than the affinity obtained for protocatechuic 


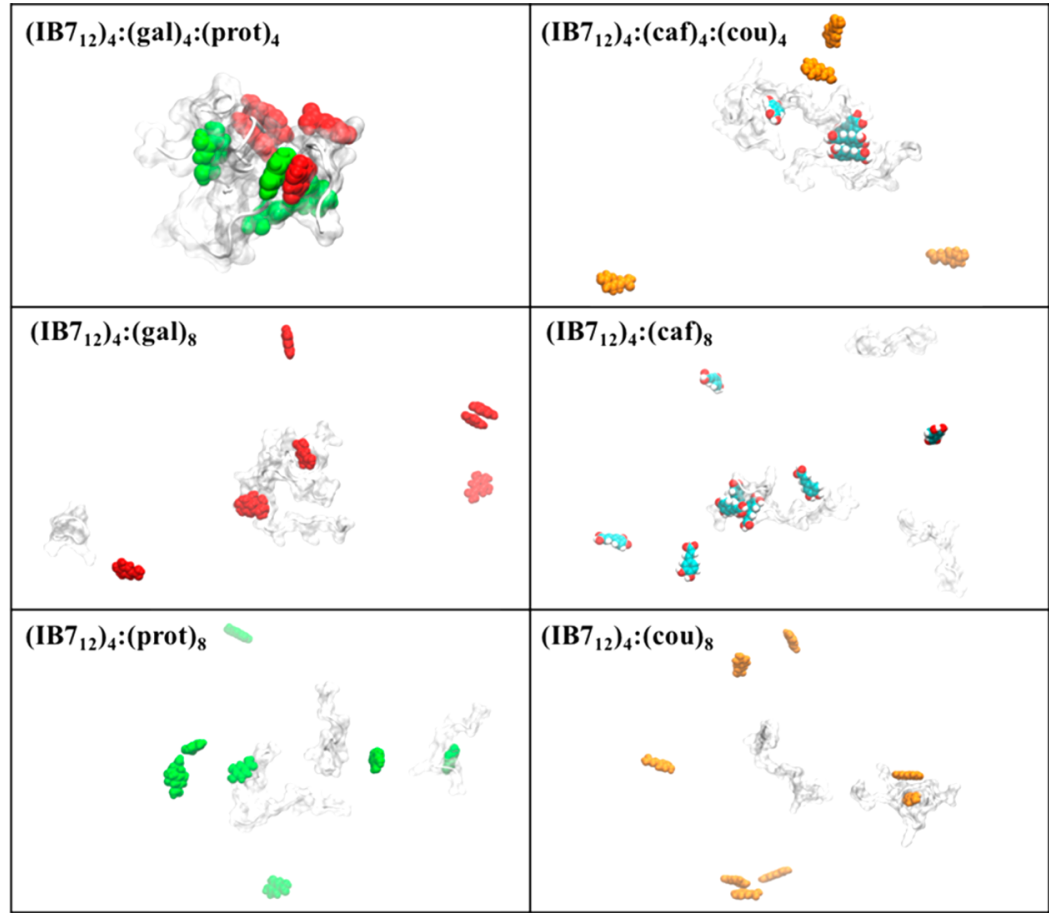

Figure 3. Illustration of representative geometries of $\left(\mathrm{IB} 7_{12}\right)_{4}:(\mathrm{gal})_{4}:(\text { prot })_{4},\left(\mathrm{IB} 7_{12}\right)_{4}:(\mathrm{gal})_{8},\left(\mathrm{IB} 7_{12}\right)_{4}:(\text { prot })_{8},\left(\mathrm{IB} 7_{12}\right)_{4}:(\mathrm{caf})_{4}:(\mathrm{cou})_{4},\left(\mathrm{IB} 7_{12}\right)_{4}:(\mathrm{caf})_{8}$, and $\left(\mathrm{IB}_{12}\right)_{4}:(\mathrm{cou})_{8}$ systems extracted from each MD simulations. The peptides are depicted with surface and cartoon and are colored in white. The gal, prot, caf, and cou molecules are depicted with vdW representation and are colored red, green, element type, and orange, respectively.

Table 2. Binding of Gal, Prot, Cat, and Cou to IB7 12 Peptide Analyzed by (i) Average of Time of Binding, (ii) Total Average Time the Molecules Remained Bound, (iii) Maximum Time the Molecules Remained Bound, and (iv) Average Total Binding Time of $(N)$ Number of Phenolic Acids Bound Simultaneously ${ }^{a}$

\begin{tabular}{|c|c|c|c|c|c|c|c|}
\hline & & $\left(\mathrm{IB} 7_{12}\right)_{4}:(\mathrm{gal})_{4}:(\mathrm{prot})_{4}$ & $\left(\mathrm{IB7}_{12}\right)_{4}:(\mathrm{gal})_{8}$ & $\left(\mathrm{IB}_{12}\right)_{4}:(\text { prot })_{8}$ & $\left(\mathrm{IB}_{12}\right)_{4}:(\mathrm{caf})_{4}:(\mathrm{cou})_{4}$ & $\left(\mathrm{IB} 7_{12}\right)_{4}:(\mathrm{caf})_{8}$ & $\left(\mathrm{IB}_{12}\right)_{4}:(\mathrm{cou})_{8}$ \\
\hline \multirow[t]{3}{*}{$\mathrm{i}$} & $\begin{array}{l}\text { av time of binding of the first phenol } \\
\text { (ns) }\end{array}$ & 18.8 & 17.2 & 20.3 & 20.9 & 13.4 & 16.5 \\
\hline & $\begin{array}{l}\text { av time of binding of the first caf or gal } \\
\text { (ns) }\end{array}$ & 20.5 & & & 22.2 & & \\
\hline & $\begin{array}{l}\text { av time of binding of the first cou or } \\
\text { prot (ns) }\end{array}$ & 17.0 & & & 18.9 & & \\
\hline \multirow[t]{3}{*}{ ii } & av total binding time (ns) & 17.0 & 8.3 & 5.1 & 8.0 & 9.8 & 10.1 \\
\hline & av total binding time of caf or gal (ns) & 17.7 & & & 11.1 & & \\
\hline & $\begin{array}{l}\text { av total binding time of cou or prot } \\
\text { (ns) }\end{array}$ & 16.2 & & & 3.0 & & \\
\hline \multirow[t]{3}{*}{ iii } & max binding time of one (ns) & 45.1 & 33.8 & 10.1 & 36.3 & 33.8 & 47.5 \\
\hline & max binding time of one caf or gal (ns) & 45.1 & & & 36.3 & & \\
\hline & $\begin{array}{l}\text { max binding time of one cou or prot } \\
\text { (ns) }\end{array}$ & 39.4 & & & 5.4 & & \\
\hline \multirow[t]{6}{*}{ iv } & av total binding time of one acid (ns) & 8.2 & 22.6 & 15.0 & 13.9 & 5.9 & 13.6 \\
\hline & $\begin{array}{l}\text { av total binding time of two } \\
\text { (simultaneously) (ns) }\end{array}$ & 10.9 & 5.4 & 3.4 & 9.4 & 8.6 & 10.4 \\
\hline & $\begin{array}{l}\text { av total binding time of three } \\
\text { (simultaneously) (ns) }\end{array}$ & 16.4 & & 1.0 & 10.3 & 8.4 & 8.5 \\
\hline & $\begin{array}{l}\text { av total binding time of four } \\
\text { (simultaneously) (ns) }\end{array}$ & 2.9 & & & 0.2 & 4.3 & 3.0 \\
\hline & $\begin{array}{l}\text { av total binding time of five phenols } \\
\text { (simultaneously) (ns) }\end{array}$ & 1.8 & & & & 3.5 & 2.3 \\
\hline & $\begin{array}{l}\text { av total binding time of six } \\
\text { (simultaneously) (ns) }\end{array}$ & 0.1 & & & & & \\
\hline $\mathrm{v}$ & $\begin{array}{l}\text { av total binding time of phenol } \\
\text { interactions (ns) }\end{array}$ & 13.4 & 6.2 & 4.3 & 4.4 & 15.4 & 11.4 \\
\hline
\end{tabular}

${ }^{a}$ The average total binding time of phenolic acid-phenolic acid interactions is also shown (v). 
acid. With regard to protocatechuic acid, protons 2 and 6 showed similar affinities $\left(K_{\mathrm{D}}=0.50\right.$ and $0.46 \mathrm{mM}$, respectively), but proton 5 showed a slightly lower affinity $\left(K_{\mathrm{D}}=0.74 \mathrm{mM}\right)$. In the case of the hydroxybenzoic acids, all of the signals showed a trend in the STD spectra at increasing concentrations and the corresponding $K_{\mathrm{D}}$ values have also been calculated. For $p$-coumaric acid, proton 6 and proton 3 showed similar affinities to the peptide $\left(K_{\mathrm{D}}=0.60\right.$ and $0.77 \mathrm{mM}$, respectively). The remaining protons did not show a clear trend in signal intensity in the STD spectra, and therefore the dissociation constants were not calculated. Proton 2 of caffeic acid showed the highest affinity to the peptide among the individual acids $\left(K_{\mathrm{D}}=0.33 \mathrm{mM}\right)$. When phenolic acids were evaluated as a mixture, some signals appeared overlapped and were jointly considered to calculate the amplification factor and the dissociation constants. This is the case of signals that correspond to protons 3 and 4 of the $p$-coumaric acid and the signal of proton 2 of caffeic acid. Signals of protons 2, 5, and 6 of $p$-coumaric acid and the signal of proton 5 of caffeic acid were also jointly considered. It is remarkable that mixture dissociation constants always presented lower values compared with the values obtained for each individual compound in the case of hydroxybenzoic acids and may justify a synergistic effect. In the case of hydroxycinnamic acids, it is more difficult to interpret the mixture of protons that have been jointly evaluated to ascertain, compare, and assign which proton presented the effect. However, proton 4 of caffeic acid presents a clear and highlighted trend that confirms the synergistic effect because a lower value compared with the value obtained for the individual compound $\left(K_{\mathrm{D}}=0.79\right.$ vs $1.21 \mathrm{mM}$ for the mixture and individual compound, respectively) has been obtained.

From these results, it could be inferred that the greater ability of these compounds to jointly interact with salivary proteins may be due to differences in the receptor-binding sites for the molecules or changes in the peptide environment due to the presence of both jointly studied acids and may justify the synergistic effect previously observed in sensory studies. ${ }^{23}$

MD Simulations. The interaction between the phenolic acids and the IB7 12 peptidic fragments in an aqueous environment were additionally assessed by computational approaches, to understand at an atomistic level the different steps that govern their recognition and binding processes. In this regard, six $\mathrm{MD}$ simulations of $50 \mathrm{~ns}$ each were carried out. Figure 3 shows a representative structure of each system throughout each MD simulation. The formation of stable complexes involving several gal, prot, caf, and cou molecules and residues of the peptides was observed. The binding of some molecules was maintained throughout the whole simulation, whereas other compounds would interact transiently and with different partners. Independent assemblies of two phenolic acid molecules in perfect alignment by their planar ring surfaces, as well as IB7 12 peptide clusters, were also seen. To compare the binding affinities of phenolic acids to $\mathrm{IB} 7_{12}$ peptides in the presence of one or two types of phenolic acids, different average and maximum time indicators considering the formation of $\left(\mathrm{IB}_{12}\right)_{1}$ : (acids $)_{n}$ complexes were analyzed for each simulation. Table 2 summarizes all of these values, whereas detailed data for all peptides and molecules are displayed in Tables S1-S7 in the Supporting Information. In general, it was observed that the first interaction between a phenol acid and an $\mathrm{IB}_{12}$ peptide occurred more rapidly in systems in which only one type of acid is present (average time of binding in Table 2). The only exception was the MD simulation involving gal and prot molecules, in which the formation of $I B 7_{12}$ :prot complexes was found to be ca. 3 ns faster than in the presence of only prot molecules in solution. The sum and the maximum of total binding time of phenolic acids is also highest in the simulation with both gal and prot (e.g., average and maximum binding time of gal are 17.7 vs 8.3 ns and 45.1 vs $33.8 \mathrm{~ns}$, respectively). The higher stability of interactions between gal and prot compounds to $\mathrm{IB} 7_{12}$ is also noticeable in the large number of molecules that are bound to one IB7 12 peptide simultaneously (maximum of 6 ) throughout the simulation with both phenolic acids. This contrasts with the only two or three molecules at maximum that bound one IB7 12 peptide in the simulations with individual gal or prot compounds. These data suggest that the presence of both gal and prot compounds in solution creates a synergistic effect that causes them to bind more easily and strongly to IB $7_{12}$ peptides. That is in good agreement with the dissociation constant values obtained from the STD-NMR experiments.

With regard to the $\mathrm{MD}$ simulations with caf and cou molecules, the binding of caf compounds occurred for longer periods in the simulation with both types of phenolic acids in the solution (11.1 vs $9.8 \mathrm{~ns}$ ). However, the cou compound seems to have a greater affinity to the proteins when they are the unique acid in the simulation (3.0 vs 10.1).

Furthermore, large assemblies of different phenolic molecules are associated with a higher interaction between the phenols and the peptides (e.g., average total binding times of gal and prot are 6.2 and $4.3 \mathrm{~ns}$ in the simulations with individual phenolics vs $13.4 \mathrm{~ns}$ in the mixed simulation).

Figure 3 also highlights that the presence of two types of phenolic acids enables a higher association between the different peptides than what is seen in simulations with each individual compound. The binding of phenolic acids to one peptide does not cause significant structural peptide rearrangement. However, during the formation of the peptide cluster, the secondary structure of each fragment changes from a linear to a coiled conformation. This structural rearrangement could create adequate binding pockets with different sizes and shapes for additional molecules and thus explain the observed synergistic effects. Interestingly, gal and prot have two fewer carbon atoms in their aliphatic ramification (as compared to caf and cou), likely facilitating their fit in the binding pockets created through the formation of $\mathrm{IB}_{12}$ clusters. This may justify the binding of a high number of gal/prot molecules during the simulation with eight phenols (maximum of six, as compared to four for caf/cou).

In agreement with other studies involving proteins and polyphenols, $^{39,40}$ our results show that the interaction of phenolic acids with $\mathrm{IB}_{12}$ peptide occurs mainly by H-bonds involving the hydroxyl groups from the polyphenols and polar groups of $\mathrm{IB} 7_{12}$, as well as hydrophobic contacts between the planar ring surfaces of polyphenols and the rings of proline residues. All phenolic acids interact mainly with the first two and the last four residues of the $\mathrm{IB}_{12}$ peptides. In addition, no great differences were observed in the peptide region of binding between the six MD simulations. The caf molecules are the ones that establish a greater number of $\mathrm{H}$-bonds, interacting with the carbonyl backbone groups of Ser1, Pro2, Gly4, Gln7, Gly8, Pro9, Pro10, and Gln12. The cou compounds interact with Pro6, Gln7, Gly8, Pro11, and Gln12 residues; the gal molecules interact with Pro6, Gly8, Pro9, Pro10, and Gln12 residues, whereas the prot compounds interact with Ser1, Pro3, Gln7, Pro8, Pro11, and Gln12 residues of peptides. 
Table 3. Solvent-Accessible Surface Area Values $\left(\AA^{2}\right)$ Obtained for Several Hydrogen Atoms of Gal and Prot Phenolic Acids throughout the MD Simulations That Involve These Molecules

\begin{tabular}{|c|c|c|c|c|c|}
\hline \multirow[b]{2}{*}{ MD simulation } & \multicolumn{2}{|c|}{ gal } & \multicolumn{3}{|c|}{ prot } \\
\hline & $\mathrm{H} 2$ & H6 & $\mathrm{H} 2$ & H5 & $\mathrm{H} 6$ \\
\hline$\left(\mathrm{IB} 7_{12}\right)_{4}:(\mathrm{gal})_{4}:(\mathrm{prot})_{4}$ & 3.13 & 2.42 & 2.82 & 4.79 & 2.05 \\
\hline$\left(\mathrm{IB} 7_{12}\right)_{4}:(\text { gal or prot })_{8}$ & 5.18 & 3.82 & 9.74 & 16.51 & 7.46 \\
\hline difference & -2.04 & -1.40 & -6.92 & -11.72 & -5.42 \\
\hline
\end{tabular}

Table 4. Solvent-Accessible Surface Area Values $\left(\AA^{2}\right)$ Obtained for Several Hydrogen Atoms of Caf and Cou Phenolic Acids throughout the MD Simulations That Involve These Molecules

\begin{tabular}{|c|c|c|c|c|c|c|c|c|}
\hline \multirow[b]{2}{*}{ MD simulation } & \multicolumn{3}{|c|}{ caf } & \multicolumn{5}{|c|}{ cou } \\
\hline & $\mathrm{H} 2$ & $\mathrm{H} 4$ & H5 & $\mathrm{H} 2$ & H3 & $\mathrm{H} 4$ & H5 & H6 \\
\hline$\left(\mathrm{IB}_{12}\right)_{4}:(\mathrm{caf})_{4}:(\mathrm{cou})_{4}$ & 2.63 & 4.70 & 7.22 & 4.77 & 10.30 & 6.47 & 11.09 & 9.71 \\
\hline$\left(\mathrm{IB}_{12}\right)_{4}:(\text { caf or cou })_{8}$ & 5.30 & 7.60 & 11.10 & 6.00 & 12.90 & 13.10 & 14.90 & 12.50 \\
\hline difference & -2.72 & -2.93 & -3.92 & -1.20 & -2.62 & -6.67 & -3.80 & -2.76 \\
\hline
\end{tabular}

The solvent-accessible surface area (SASA) values were determined for the hydrogen atoms of all phenolic acids for which the NMR results were obtained during each MD simulation. These values (shown in Tables 3 and 4) evaluate the surface area of each atom that is accessible to solvent, which could indicate its availability for binding other solute molecules. The SASA values of hydrogen atoms from gal, prot, caf, and cou molecules decrease an average of $1.72,8.02,3.19$, and 3.41 $\AA^{2}$, respectively, when two different phenols are mixed in solution, which fortifies the higher binding extension previously observed for these molecules in these conditions.

To summarize, interactions between wine phenolic acids and the peptide fragment $\mathrm{IB}_{12}$, which contains a characteristic sequence of proline-rich proteins, have been observed by STDNMR spectroscopy. The obtained results showed the ability of these compounds to interact with salivary proteins and may justify the synergistic effect observed in previous studies. Moreover, further insights into the mechanisms of action have been obtained using MD simulations. It could be inferred that the greater ability of these compounds to jointly interact with salivary proteins may be due to differences in the receptorbinding sites for the molecules or changes in the peptide environment due to the presence of both jointly studied acids and may justify the synergistic effect previously observed. ${ }^{23}$

\section{ASSOCIATED CONTENT}

\section{(5) Supporting Information}

The Supporting Information is available free of charge on the ACS Publications website at DOI: 10.1021/acs.jafc.6b05414.

Binding affinities values obtained in this study (PDF)

\section{AUTHOR INFORMATION}

\section{Corresponding Author}

*(M.T.E.-B.) Phone: +34 923294 537. Fax: +34 923294515.

E-mail: escriban@usal.es.

\section{ORCID $\odot$}

José Miguel Hernández-Hierro: 0000-0002-2329-3024

Francisco J. Heredia: 0000-0002-3849-8284

María Teresa Escribano-Bailón: 0000-0001-6875-2565

\section{Funding}

We thank the Spanish MINECO (AGL2014-58486-C2). J.M.H.-H. thanks JPI 2015 (Banco Santander) and V-PPI (Universidad de Sevilla) for mobility grants. R.F.-G. thanks
Fundación Martin Escudero for a postdoctoral fellowship. N.F.B. thankfully acknowledges her IF starting grant (IF/ 01355/2014) by Fundação para a Ciência e Tecnologia (FCT). N.V. also thanks FCT for his IF starting grant (IF/00092/ 2014). We further acknowledge FCT for funding UCIBIOREQUIMTE and LAQV-REQUIMTE research units through projects UID/MULTI/04378/2013 and UID/QUI/50006/ 2013, respectively.

Notes

The authors declare no competing financial interest.

\section{ACKNOWLEDGMENTS}

We thank Dr. Mariana Andrade for help in setting up and conducting the STD-NMR experiments.

\section{ABBREVIATIONS USED}

Gal, gallic acid; prot, protocatechuic acid; caf, caffeic acid; cou, $p$-coumaric acid; STD-NMR, saturation-transfer difference NMR spectroscopy; MD, molecular dynamics; SASA, solventaccessible surface area

\section{REFERENCES}

(1) Crozier, A.; Clifford, M. N.; Ashihara, H. Plant Secondary Metabolites. Occurrence, Structure and Role in the Human Diet; Blackwell Publishing: Oxford, UK, 2006.

(2) Koes, R. E.; Quattrocchio, F.; Mol, J. N. M. The flavonoid biosynthetic pathway in plants: function and evolution. BioEssays 1994, 16, 123-132.

(3) Condelli, N.; Dinnella, C.; Cerone, A.; Monteleone, E.; Bertuccioli, M. Prediction of perceived astringency induced by phenolic compounds. II: Criteria for panel selection and preliminary application on wine samples. Food Qual. Prefer. 2006, 17, 96-107.

(4) Le Moigne, M.; Maury, C.; Bertrand, D.; Jourjon, F. Sensory and instrumental characterisation of Cabernet Franc grapes according to ripening stages and growing location. Food Qual. Prefer. 2008, 19, 220-231.

(5) Sáenz-Navajas, M.-P.; Ferreira, V.; Dizy, M.; Fernández-Zurbano, $\mathrm{P}$. Characterization of taste-active fractions in red wine combining HPLC fractionation, sensory analysis and ultra performance liquid chromatography coupled with mass spectrometry detection. Anal. Chim. Acta 2010, 673, 151-159.

(6) Hufnagel, J. C.; Hofmann, T. Orosensory-directed identification of astringent mouthfeel and bitter-tasting compounds in red wine. J. Agric. Food Chem. 2008, 56, 1376-1386.

(7) Challacombe, C. A.; Abdel-Aal, E. S. M.; Seetharaman, K.; Duizer, L. M. Influence of phenolic acid content on sensory perception of 
bread and crackers made from red or white wheat. J. Cereal Sci. 2012, 56, 181-188.

(8) de Freitas, V.; Mateus, N. Protein/polyphenol interactions: past and present contributions. mechanisms of astringency perception. Curr. Org. Chem. 2012, 16, 724-746.

(9) Scollary, G. R.; Pásti, G.; Kállay, M.; Blackman, J.; Clark, A. C. Astringency response of red wines: potential role of molecular assembly. Trends Food Sci. Technol. 2012, 27, 25-36.

(10) Canon, F.; Ballivian, R.; Chirot, F.; Antoine, R.; SarniManchado, P.; Lemoine, J.; Dugourd, P. Folding of a salivary intrinsically disordered protein upon binding to tannins. J. Am. Chem. Soc. 2011, 133, 7847-7852.

(11) Canon, F.; Giuliani, A.; Paté, F.; Sarni-Manchado, P. Ability of a salivary intrinsically unstructured protein to bind different tannin targets revealed by mass spectrometry. Anal. Bioanal. Chem. 2010, 398, $815-822$.

(12) Canon, F.; Ployon, S.; Mazauric, J.-P.; Sarni-Manchado, P.; Réfrégiers, M.; Giuliani, A.; Cheynier, V. Binding site of different tannins on a human salivary proline-rich protein evidenced by dissociative photoionization tandem mass spectrometry. Tetrahedron 2015, 71, 3039-3044.

(13) Cala, O.; Dufourc, E. J.; Fouquet, E.; Manigand, C.; Laguerre, M.; Pianet, I. The colloidal state of tannins impacts the nature of their interaction with proteins: the case of salivary proline-rich protein/ procyanidins binding. Langmuir 2012, 28, 17410-17418.

(14) Schwarz, B.; Hofmann, T. Is there a direct relationship between oral astringency and human salivary protein binding? Eur. Food Res. Technol. 2008, 227, 1693-1698.

(15) Gibbins, H. L.; Carpenter, G. H. Alternative mechanisms of astringency-what is the role of saliva? J. Texture Stud. 2013, 44, 364375.

(16) Soares, S.; Ferrer-Gallego, R.; Brandao, E.; Silva, M.; Mateus, N.; Freitas, V. Contribution of human oral cells to astringency by binding salivary protein/tannin complexes. J. Agric. Food Chem. 2016, 64, 7823-7828.

(17) Delcour, J. A.; Vandenberghe, M. M.; Corten, P. F.; Dondeyne, P. Flavor thresholds of polyphenolics in water. Am. J. Enol. Vitic. 1984, 35, 134-136.

(18) Kielhorn, S.; Thorngate, J. H., III Oral sensations associated with the flavan-3-ols (+)-catechin and (-)-epicatechin. Food Qual. Prefer. 1999, 10, 109-116.

(19) Lesschaeve, I.; Noble, A. C. Polyphenols: factors influencing their sensory properties and their effects on food and beverage preferences. Am. J. Clin. Nutr. 2005, 81, 330S-335S.

(20) Peleg, H.; Gacon, K.; Schlich, P.; Noble, A. C. Bitterness and astringency of flavan-3-ol monomers, dimers and trimers. J. Sci. Food Agric. 1999, 79, 1123-1128.

(21) Vidal, S.; Francis, L.; Noble, A.; Kwiatkowski, M.; Cheynier, V.; Waters, E. Taste and mouth-feel properties of different types of tanninlike polyphenolic compounds and anthocyanins in wine. Anal. Chim. Acta 2004, 513, 57-65.

(22) de Freitas, V.; Mateus, N. Structural features of procyanidin interactions with salivary proteins. J. Agric. Food Chem. 2001, 49, 940945.

(23) Ferrer-Gallego, R.; Hernández-Hierro, J. M.; Rivas-Gonzalo, J. C.; Escribano-Bailón, M. T. Sensory evaluation of bitterness and astringency sub-qualities of wine phenolic compounds: synergistic effect and modulation by aromas. Food Res. Int. 2014, 62, 1100-1107.

(24) Cala, O.; Fabre, S.; Pinaud, N.; Dufourc, E. J.; Fouquet, E.; Laguerre, M.; Pianet, I. Towards a molecular interpretation of astringency: synthesis, 3D structure, colloidal state, and human saliva protein recognition of procyanidins. Planta Med. 2011, 77, 11161122.

(25) Ferrer-Gallego, R.; Quijada-Morín, N.; Brás, N. F.; Gomes, P.; de Freitas, V.; Rivas-Gonzalo, J. C.; Escribano-Bailón, M. T. Characterization of sensory properties of flavanols-a molecular dynamic approach. Chem. Senses 2015, 40, 381-390.

(26) Canon, F.; Pate, F.; Cheynier, V.; Sarni-Manchado, P.; Giuliani, A.; Perez, J.; Durand, D.; Li, J.; Cabane, B. Aggregation of the salivary proline-rich protein IB5 in the presence of the tannin EgCG. Langmuir 2013, 29, 1926-1937.

(27) Charlton, A. J.; Baxter, N. J.; Khan, M. L.; Moir, A. J. G.; Haslam, E.; Davies, A. P.; Williamson, M. P. Polyphenol/peptide binding and precipitation. J. Agric. Food Chem. 2002, 50, 1593-1601.

(28) Ferrer-Gallego, R.; Soares, S.; Mateus, N.; Rivas-Gonzalo, J. C.; Escribano-Bailón, M. T.; De Freitas, V. New anthocyanin-human salivary protein complexes. Langmuir 2015, 31, 8392-8401.

(29) Goncalves, R.; Mateus, N.; Pianet, I.; Laguerre, M.; de Freitas, V. Mechanisms of tannin-induced trypsin inhibition: a molecular approach. Langmuir 2011, 27, 13122-13129.

(30) Viegas, A.; Manso, J.; Nobrega, F. L.; Cabrita, E. J. Saturationtransfer difference (STD) NMR: a simple and fast method for ligand screening and characterization of protein binding. J. Chem. Educ. 2011, 88, 990-994.

(31) Frisch, M. J., Trucks, G. W.; Schlegel, H. B.; Scuseria, G. E.; Robb, M. A.; Cheeseman, J. R.; Scalmani, G.; Barone, V.; Mennucci, B.; Petersson, G. A.; Nakatsuji, H.; Caricato, M.; Li, X.; Hratchian, H. P.; Izmaylov, A. F.; Bloino, J.; Zheng, G.; Sonnenberg, J. L.; Hada, M.; Ehara, M.; Toyota, K.; Fukuda, R.; Hasegawa, J.; Ishida, M.; Nakajima, T.; Honda, Y.; Kitao, O.; Nakai, H.; Vreven, T.; Montgomery, Jr., J. A.; Peralta, J. E.; Ogliaro, F.; Bearpark, M.; Heyd, J. J.; Brothers, E.; Kudin, K. N.; Staroverov, V. N.; Kobayashi, R.; Normand, J.; Raghavachari, K.; Rendell, A.; Burant, J. C.; Iyengar, S. S.; Tomasi, J.; Cossi, M.; Rega, N.; Millam, N. J.; Klene, M.; Knox, J. E.; Cross, J. B.; Bakken, V.; Adamo, C.; Jaramillo, J.; Gomperts, R.; Stratmann, R. E.; Yazyev, O.; Austin, A. J.; Cammi, R.; Pomelli, C.; Ochterski, J. W.; Martin, R. L.; Morokuma, K.; Zakrzewski, V. G.; Voth, G. A.; Salvador, P.; Dannenberg, J. J.; Dapprich, S.; Daniels, A. D.; Farkas, Ö.; Foresman, J. B.; Ortiz, J. V.; Cioslowski, J.; Fox, D. J. Gaussian 09, revision A.1; Gaussian, Inc.: Wallingford, CT, USA, 2009.

(32) Bayly, C. I.; Cieplak, P.; Cornell, W. D.; Kollman, P. A. A wellbehaved electrostatic potential based method using charge restraints for deriving atomic charges - the RESP model. J. Phys. Chem. 1993, 97, 10269-10280.

(33) Wang, J. M.; Wolf, R. M.; Caldwell, J. W.; Kollman, P. A.; Case, D. A. Development and testing of a general amber force field. J. Comput. Chem. 2004, 25, 1157-1174.

(34) Hornak, V.; Abel, R.; Okur, A.; Strockbine, B.; Roitberg, A.; Simmerling, C. Comparison of multiple Amber force fields and development of improved protein backbone parameters. Proteins: Struct., Funct., Genet. 2006, 65, 712-725.

(35) Izaguirre, J. A.; Catarello, D. P.; Wozniak, J. M.; Skeel, R. D. Langevin stabilization of molecular dynamics. J. Chem. Phys. 2001, 114, 2090-2098.

(36) Case, D. A.; Darden, T. A.; Cheatham, T. E.; Simmerling, C. L.; Wang, J.; Duke, R. E.; Luo, R.; Walker, R. C.; Zhang, W.; Merz, K. M.; Roberts, B.; Hayik, S.; Roitberg, A.; Seabra, G.; Swails, J.; Goetz, A. W.; Kolossváry, I.; Wong, K. F.; Paesani, F.; Vanicek, J.; Wolf, R. M.; Liu, J.; Wu, X.; Brozell, S. R.; Steinbrecher, T.; Gohlke, H.; Cai, Q.; Ye, X.; Wang, J.; Hsieh, M. J.; Cui, G.; Roe, D. R.; Mathews, D. H.; Seetin, M. G.; Salomon-Ferrer, R.; Sagui, C.; Babin, V.; Luchko, T.; Gusarov, S.; Kovalenko, A.; Kollman, P. A. AMBER 12; University of California: San Francisco, CA, USA, 2012.

(37) Ryckaert, J. P.; Ciccotti, G.; Berendsen, H. J. C. Numericalintegration of Cartesian equations of motion of a system with constraints - molecular-dynamics of $n$-alkanes. J. Comput. Phys. 1977, $23,327-341$.

(38) Essmann, U.; Perera, L.; Berkowitz, M. L.; Darden, T.; Lee, H.; Pedersen, L. G. A smooth particle mesh Ewald method. J. Chem. Phys. 1995, 103, 8577-8593.

(39) de Freitas, V.; Carvalho, E.; Mateus, N. Study of carbohydrate influence on protein-tannin aggregation by nephelometry. Food Chem. 2003, 81, 503-509.

(40) Simon, C.; Barathieu, K.; Laguerre, M.; Schmitter, J.-M.; Fouquet, E.; Pianet, I.; Dufourc, E. J. Three-dimensional structure and dynamics of wine tannin-saliva protein complexes. A multitechnique approach. Biochemistry 2003, 42, 10385-10395. 